- An investigation of where the Israeli public seek advice on mouth ulcers.

- Nearly one third of those surveyed had a history of mouth ulceration.

- Lay people could not distinguish an ulcer with features that would strongly suggest a malignant neoplasm from other types of mouth ulcer.

- The vast majority would first seek advice from their general medical practitioner.

- Less than $20 \%$ would first approach a general dental practitioner.

\title{
Mouth ulcers: a study of where members of the general public might seek advice
}

\author{
Y. Gill ${ }^{1}$ and C. Scully ${ }^{2}$
}

\begin{abstract}
Objective To investigate where the public seek advice about mouth ulcers and to what extent the public approach the community pharmacy for advice.
\end{abstract}

Subjects and methods One thousand members of the general public were randomly chosen and surveyed throughout the day in the main shopping streets of two towns in Israel, Haifa and Tel Aviv. All participants were presented with four standard verbal questions designed to identify reactions to and past experience of mouth ulcers. All responses were recorded immediately on to data sheets and transferred to a computer for analysis of frequencies and percentages and Chi-square analysis.

Results Nearly one third of those surveyed admitted to a history of mouth ulceration. The vast majority (66-69\%) would first approach their general medical practitioner for advice, 13-17\% would first approach a general dental practitioner, and only a small minority of the public (4-10\%) would first approach the community pharmacy. Lay persons could not distinguish an ulcer with features that would strongly suggest a malignant neoplasm from other types of mouth ulcer. Conclusions The dental profession needs to collaborate more closely with the medical and pharmaceutical professions in order to offer patients better access to information and care.

\section{INTRODUCTION}

Oral ulcers are common and although most are caused by trauma or are recurrent aphthae, some may be the manifestation of an underlying systemic disease or may be due to malignant disease, mainly oral cancer..$^{1-4}$ Malabsorption states,

'Dental Practitioner/Honorary Lecturer, 7 Ranak Street, Ahusa, Haifa, Israel; ${ }^{2 *}$ Dean/ Director of Studies and Research, Eastman Dental Institute, University College London, 256 Gray's Inn Road, London, WC1X 8LD

${ }^{*}$ Correspondence to: Professor Crispian Scully CBE

Email: c.scully@eastman.ucl.ac.uk

Online article number E16

Refereed Paper - accepted 9 June 2006

DOI: 10.1038/bdj.2007.82

${ }^{\circ}$ British Dental Journal 2007; 202: E16 haematological disorders, cutaneous diseases, connective diseases, drugs and infections including HIV should always be born in mind in the aetiology of mouth ulcers. ${ }^{1-4}$

Studies from a number of countries have shown that persons suffering from mouth ulcers may seek advice from dental or medical practitioners; $;^{5-17}$ may be encouraged by press advertising to self-medicate using proprietary preparations that are rarely of scientifically proven value; may approach the community pharmacy for advice; ${ }^{18-21}$ or may investigate the effects of complementary medicine. In some countries at least, the evidence suggests that the latter delays diagnosis. ${ }^{22}$

However, there is little data on from whom patients actually do seek advice. Therefore, this study was conducted to investigate the views of the public as to where they would seek advice about mouth ulcers.

\section{SUBJECTS AND METHODS}

One thousand adult members of the general public were randomly chosen and surveyed throughout the day in the main shopping streets of two towns in Israel, Haifa and Tel Aviv, by a researcher who was an unidentified dentist (YG).

All participants were presented with four standard verbal questions.

1. The first question presented (The recommendations for a persistent mouth ulcer), designed to identify reactions to a patient with possible mouth cancer, was:

'If an immediate relative of yours who is late middle aged or elderly (ie over the age of 50 years), suffered from a persistent ulcer on the side of the tongue for more than six months, which of the following would you recommend:

a) approach the community pharmacy

b) approach a general dental practitioner

c) approach a general medical practitioner

d) any other desired option (specify).'

Only one answer was permissible.

2.The second question presented (The recommendations for recurrent mouth ulcers), designed to identify reactions to a patient with probable aphthae, was: 
'If you had suffered from recurrent mouth ulcers for the last few years what would you recommend?'

The same four options noted above were given. Only one answer was permissible.

3. The third question recorded the questioned person's past personal experience of the condition described in question 1 above (Past experience with mouth ulceration: persistent tongue ulcer).

4. The fourth question recorded the person's past personal experience of the condition described in question 2 above (Past experience with mouth ulceration: recurrent mouth ulcers).

All responses were recorded immediately onto data sheets and transferred to computer for analysing frequencies and percentages and for chi-square analysis.

\section{RESULTS}

The participants who were prepared to assist the survey by answering all questions made up a study group who were composed of 560 adults (56\%) out of whom 330 (58.9\%) were female and 230 (41.1\%) were male. Most of the study group were in the third, fourth and fifth decade age groups - 163 $(29.1 \%), 190(33.9 \%)$ and $121(21.6 \%)$ respectively. Those in the sixth, seventh and eighth decades counted for the rest -47 (8.4\%), 30 (5.4\%) and 9 (1.6\%) respectively.

\section{The recommendations for a persistent mouth ulcer}

Most of the study group (68.6\%) would have recommended first approaching the general medical practitioner for advice, and only $13.4 \%$ would have recommended an approach to a dentist. Some $9.6 \%$ of study group participants would recommend an approach to a pharmacy and 8.4\% would have recommended other options. The 'other' options were as follows: most (78.7\%) suggested doing nothing, and the remainder (21.3\%) suggested approaching a specialist - maxillofacial and oral surgery or oral medicine (8.5\%), dermatologist (4.3\%), ENT (4.3\%), hospital internal medicine $(2.1 \%)$ or alternative medicine $(2.1 \%)$.

\section{The recommendations for recurrent mouth ulcers}

Most of the study group stated they would have chosen to approach their general medical practitioner (65.9\%) and only $17.1 \%$ would have chosen first to approach their dentist for advice. Only $3.6 \%$ of the study group would have chosen to approach their community pharmacy and 13.4\% would have chosen other options. Most of those in the latter group would have sought advice in a specialised centre or hospital (48\%) but $28 \%$ would have done nothing about the condition and the rest would have approached specialists including those in maxillofacial surgery or oral medicine (9.5\%), dermatology (8\%), ENT (2.7\%), hospital internal medicine (1.4\%) and alternative medicine $(1.4 \%)$.

\section{3. and 4. Past experience with mouth ulceration}

of the 560 in the study group, some 30.5\% could recall experiencing oral ulceration. Nearly $20 \%$ had past experience with a single fairly persistent ulcer (all had eventually healed, usually within three weeks) while $11.3 \%$ had experienced recurrent oral ulcers.

Further statistical analysis using the chi-square test revealed that statistically there were no significant differences between the results obtained from the different age and sex groups as well as between the results obtained to the first question, ie the persistent ulcer, and the second question, ie the recurrent ulcers.

\section{DISCUSSION}

The results of the present study show that 56\% of the adult general public surveyed were prepared to co-operate in this survey. Although this is not a large response rate, nevertheless the large sample does mean that the responses might be fairly representative of the population in question. Of these, about one third (31\%) believed they had suffered from oral ulceration, and about 12\% reported they had suffered from recurrent mouth ulcers. These findings are consistent with results from similar studies, though point studies show lower figures. ${ }^{23-26}$

The findings as to where the public would seek advice are interesting. Our results indicate that the vast majority of the public would first approach a general medical practitioner for advice: indeed, only 13-17\% would first approach a dentist. A somewhat lower number (4-10\%) would first go to a pharmacy for advice, were they to suffer mouth ulceration. These findings are of special interest since dentists clearly have considerably more training and knowledge regarding the diagnosis and management of mouth ulcers than do most medical or pharmacy practitioners. The evidence indicates that few medical students or doctors receive any training in oral disease and few medical texts contain much data about the mouth, ${ }^{27}$ though some journals now offer continuing professional education in this area. ${ }^{28}$ Indeed, in one UK study, medical staff were sent 10 oral disease cases to diagnose ${ }^{29}$ and only $28 \%$ diagnosed cases correctly, compared with $88.7 \%$ cases diagnosed correctly by dentists. Only 11 of the 21 UK medical schools who responded to the survey about the teaching of oral pathology/medicine in their medical curricula, suggested they had any coverage of the area, the authors of the report concluding that doctors and medical students are inadequately educated about oral diseases. ${ }^{29}$

Also of interest is the fact that, despite advertisements in the lay press that encourage the public to approach community pharmacies with oral (and other) problems, only a small minority of the public would first approach the community pharmacy for advice, at least in Israel, in this study. Some patients do seek advice from community pharmacies, but studies in UK and USA have confirmed the limited understanding of some pharmacy staff offering advice directly to patients, regarding the potential importance of mouth ulcers and the possibility of neoplasia. ${ }^{18-21}$ Unsurprisingly, if patients seek advice in a pharmacy, the quality of advice given is dependent on whether the respondent is a pharmacist or a community pharmacy assistant. ${ }^{21}$ Although pharmacies can play a very useful role in community health care, patients with symptoms which necessitate medical or dental attention are best not advised to seek such opinions unless they can be certain they will receive professional advice; the evidence indicates that shop salespersons (community pharmacy assistants) are frequently consulted, rather than the qualified pharmacists. ${ }^{18-}$ ${ }^{21}$ Thus, although there is no doubt that pharmacies could be helpful in dealing with oral health problems, ${ }^{30,31}$ this situation is of some concern since although few mouth ulcers are of systemic importance (most are of traumatic aetiology or are 
recurrent aphthae), malignant disease or systemic disorders underlie some mouth ulcers. ${ }^{1-4}$

Most important are malignant ulcers, typically squamous carcinomas, since the earlier these are diagnosed the better the prognosis. Many malignant ulcers present as a single persistent ulcer, typically in the older male and on the lateral margin of the tongue and there is still often an inordinate delay before patients present, though most studies in the English-speaking world show that both medical and dental practitioners will refer patients with oral cancer to a relevant hospital department after only a relatively short period of observation. ${ }^{5-17,22}$

A small group of patients with aphthae have identifiable and often treatable predisposing factors, such as a haematinic deficiency or coeliac disease. Mouth ulcers can also be caused by some other blood dyscrasias, dermatoses and infections such as syphilis, tuberculosis or HIV infection. ${ }^{4}$ In all of these, medical and/or dental care is indicated.

In conclusion, in order to offer patients better access to information and care, it would seem logical for the dental profession to collaborate more closely with the medical and pharmaceutical professions, in order to offer them educational material covering orofacial health and disease.

1. Scully C, Flint S, Porter S R, Moos K. Oral and maxillofacial diseases. 3rd ed. London: Taylor \&t Francis, 2004.

2. Scully C. Aphthous ulceration. New Eng/ J Med 2006; 355: 41-48.

3. Scully C, Felix D H. Oral medicine - update for the dental practitioner 1. Aphthous and other common ulcers. Br Dent J 2005; 199: 259-264.

4. Scully C, Felix D H. Oral medicine - update for the dental practitioner. 2. Mouth ulcers of more serious connotation. Br Dent J 2005; 199: 339-343.

5. Scully C, Malamos D, Levers B G, Porter S R, Prime S S. Sources and patterns of referrals of oral cancer: the role of general practitioners. Br Med J (Clin Res Ed) 1986; 293: 599-601.

6. Guggenheimer J, Verbin R S, Johnson J T, Horkowitz C A, Myers E N. Factors delaying the diagnosis of oral and oropharyngeal carcinomas. Cancer 1989; 64: 932-935.

7. Schnetler J F. Oral cancer diagnosis and delays in referral. Br J Oral Maxillofac Surg 1992; 30: 210-213.

8. Dimitroulis $G$, Reade $P$, Wiesenfeld $D$. Referral patterns of patients with oral squamous cell carcinoma, Australia. Eur J Cancer B Oral Oncol 1992; 28B: 23-27.

9. Kowalski L P, Franco E L, Torloni $\mathrm{H}$ et al. Lateness of diagnosis of oral and oropharyngeal carcinoma: factors related to the tumour, the patient and health professionals. Eur J Cancer B Oral Oncol 1994; 30B: 167-173.
10. Allison $P$, Locker $D$, Feine J $S$. The role of diagnostic delays in the prognosis of oral cancer: a review of the literature. Oral Oncol 1998; 34: 161-170.

11. Hollows P, McAndrew P G, Perini M G. Delays in the referral and treatment of oral squamous cell carcinoma. Br Dent J 2000; 188: 262-265.

12. Pitiphat W, DiehI S R, Laskaris G, Cartsos V, Douglass C W, Zavras A I. Factors associated with delay in the diagnosis of oral cancer. J Dent Res 2002; 81: 192-197.

13. Onizawa K, Nishihara K, Yamagata K, Yusa H, Yanagawa T, Yoshida H. Factors associated with diagnostic delay of oral squamous cell carcinoma. Oral Oncol 2003; 39: 781-788.

14. McLeod N M, Saeed N R, Ali E A. Oral cancer: delays in referral and diagnosis persist. Br Dent J 2005; 198: 681-684.

15. Tromp D M, Brouha X D, Hordijk G J, Winnubst J A, de Leeuw R J. Patient and tumour factors associated with advanced carcinomas of the head and neck. Oral Oncol 2005; 41: 313-319.

16. Diz Dios P, Padron Gonzalez N, Seoane Leston J, Tomas Carmona I, Limeres Posse J, Varela-Centelles P. 'Scheduling delay' in oral cancer diagnosis: a new protagonist. Oral Oncol 2005; 41: 142-146.

17. Gordon M, Rishpon S, Gorski M. [Delayed diagnosis of carcinoma of the oral cavity]. Harefuah 2005; 144: 243-245, 304, 303. [In Hebrew].

18. Scully C, Gill Y, Gill Z. How community pharmacy staff manage a patient with possible oral cancer. Br J Oral Maxillofac Surg 1989; 27: 16-21.

19. Leonard M S, Isetts B J, Leonard CX. Response of community pharmacists to potential oral carcinoma. J Am Pharm Assoc (Wash) 1996; NS36: 203-205.

20. Gill Y, Gill Z, Scully C. How community pharmacy staff manage recurrent mouth ulcers. Pharmaceutical J 1988; 241: 82-83.

21. Evans M J, Gibbons A J. Advice given in community pharmacies to patients with possible oral carcinoma. Br J Oral Maxillofac Surg 2005; 43: 253-255.

22. Kerdpon D, Sriplung H. Factors related to advanced stage oral squamous cell carcinoma in southern Thailand. Oral Oncol 2001; 37: 216-221.

23. Axell T, Henricsson V. The occurrence of recurrent aphthous ulcers in an adult Swedish population. Acta Odontol Scand 1985; 43: 121-125.

24. Andreasen J O, Pindborg J J, Hjorting-Hansen E, Axell T. Oral health care: more than caries and periodontal disease. A survey of epidemiological studies on oral disease. Int Dent J 1986; 36: 207-214.

25. Gherunpong S, Tsakos G, Sheiham A. The prevalence and severity of oral impacts on daily performances in Thai primary school children. Health Qual Life Outcomes $2004 ; 2: 57$.

26. Shulman J D, Beach M M, Rivera-Hidalgo F. The prevalence of oral mucosal lesions in U.S. adults: data from the Third National Health and Nutrition Examination Survey, 1988-1994. J Am Dent Assoc 2004; 135: 1279-1286.

27. Bowden J, Scully C. Dentistry and total oral health. Br Med J 1989; 298: 186.

28. Scully C. An ABC of oral health. 1st ed. London: British Medical Journal Books, 2000.

29. McCann P J, Sweeney M P, Gibson J, Bagg J. Training in oral disease, diagnosis and treatment for medical students and doctors in the United Kingdom. Br J Oral Maxillofac Surg 2005; 43: 61-64.

30. Dickinson C, Howlett J A, Bulman J S. The role of the community pharmacist as a dental health adviser. Community Dent Health 1995; 12: 235-237.

31. Spina M B. Community, hospital, and research pharmacists involved in dental health problems. TIC 1977; 36: 4-5. 